\title{
Deep trap-induced dynamic on-resistance degradation in GaN-on-Si power MISHEMTs
}

\author{
A. Sasikumar ${ }^{\mathrm{a}}$, A. R. Arehart ${ }^{\mathrm{a}}$, D. W. Cardwell ${ }^{\mathrm{a}}$, C. M. Jackson ${ }^{\mathrm{a}}$, W. Sun ${ }^{\mathrm{a}}, \mathrm{Z}$. \\ Zhang $^{\mathrm{a}}$, and S. A. Ringel ${ }^{\mathrm{a},{ }^{*}}$ \\ ${ }^{a}$ Department of Electrical and Computer Engineering, The Ohio State \\ University, Columbus, Ohio 43210, USA.
}

\begin{abstract}
Identification and characterization of a single, deep trap causing large increases in the on-resistance of GaN-on-Si power metal-insulator-semiconductorhigh electron mobility transistors(MISHEMTs) is reported. This is achieved by using HEMT-based deep level optical spectroscopy (DLOS) and related methods in conjunction with high voltage off-state $V_{D S}$ switching up to $400 \mathrm{~V}$. A trap with an activation energy of $\sim \mathrm{E}_{\mathrm{C}}-2 \mathrm{eV}$ that is physically located in the drain-access region of the MISHEMTis shown to be the primary source of an increase of the dynamic onresistance increase by as much as $\sim 9$ times at $400 \mathrm{~V}$ operation. Comparisons of trap signatures extracted from the MISHEMT with capacitance-based DLOS measurements of simple Schottky-diodetest-structures showing the same, dominant trap signature suggests that the physical defect is located within the GaN buffer and is not a surface or insulator-relateddefect.Abuffer trap based model is presented to explain the observed on-resistance degradation effects in the MISHEMTs during high voltage switching.
\end{abstract}

Keywords: Gallium nitride, high electron mobility transistors (HEMTs), traps, dynamic on-resistance, degradation, reliability, high voltage, deep level transient spectroscopy (DLTS), deep level optical spectroscopy (DLOS)

*Corresponding author. Address: 205 Dreese Laboratories, 2015 Neil Avenue, Columbus, OH 43210, United States. Tel.: (614) 292-6904; fax: (614) 292-9562

E-mail address: ringel.5@osu.edu 


\section{Introduction}

GaN high electron mobility transistors (HEMTs) are at the cusp of revolutionizing power electronic devices thanks to their low channel resistances, large breakdown fields, and low stored charge that enables fast and highly efficiency switching operationat high voltages [1-5]. These benefits coupled with cost-advantages of growing on Si substrates have enabled commercialization of GaN-based HEMTs in large volumes for high voltage switching applications $[1,2]$.Despite the progress in achieving high quality epitaxy of IIINitride semiconductors on $\mathrm{Si}$, the problem of minimizing crystal defects (point and extended) in the III-Nitride films is still not trivial [6, 7].Defects can manifest as deep states in the energy bandgap that participate in charge trapping and thereby degrade HEMT performance and affect their long-term reliability [8-16].Furthermore, the behavior of traps in high field conditions for power GaN HEMTs is not well understood where the application of high voltages itself may also lead to formation/activation of additional electrically active defects. To date there have been sparse studies on trapping effects in GaN-on-Si metal-insulator-semiconductor high electron mobility transistors (MISHEMTs) and fewer still directly correlating the high voltage switching impact on device metrics to traps $[17,18]$. One figure of merit power engineers are particularly concerned with is the transistor ON-resistance, $\mathrm{R}_{\mathrm{ON}}[2,4,17-20]$.Dynamic $\mathrm{R}_{\mathrm{ON}}$ is a timedependent change in resistance observed after switching from a high off-state drain-tosource voltage $\left(\mathrm{V}_{\mathrm{DS}}\right)$ condition.Thisdynamic $\mathrm{R}_{\mathrm{ON}}$, over time, recovers to a steady-state $\mathrm{R}_{\mathrm{ON}}$ condition that matches the resistance originally measured in the virgin HEMT, and thus traps are a very likely source for this degradation [2, 4, 17-20]. 
Therefore, the purpose of this study is to identify traps in Ga-on-Si power MISHEMTs at meaningful operating conditions, i.e. at high voltage operation, and to correlate their behavior with observed modes of device degradation. To achieve this, we report here the successful adaptation of the defect spectroscopy methods known as constant drain current deep level optical spectroscopy and deep level transient spectroscopy ( $\mathrm{CI}_{\mathrm{D}}$-DLOS/DLTS), which have enabled direct connections between specific traps and degradation modes of AlGaN/GaN RF HEMTs, to now be applicable for high voltage switching studies, achieving measurements of up to a $\mathrm{V}_{\mathrm{DS}}$ of $600 \mathrm{~V}$ in off-state switching. A dominant deep trap, at $\mathrm{E}_{\mathrm{C}}-2.0 \mathrm{eV}$ is revealed as the root cause of complete current collapse under high voltage switching for the GaN-on-Si MISHEMTs studied here. These observations represent an entirely different degradation mode compared with RF GaN HEMTs studied to date[11]-[16]. Additional defect spectroscopy studies of $\mathrm{AlGaN} / \mathrm{GaN}$ on $\mathrm{Si}$ heterostructures processed into simple Schottky diodes suggest that this trap exists only within the GaN buffer and further analysis shows it to be activated only in the drain access region extending beyond the field plates of the MISHEMT.

\section{Experimental}

The transistors described in this study are AlGaN/GaN HEMTs grown on6-inch Si (111) substrates with dielectric in the access regions and under the gate. The buffer design of these devices is similar to what has been published in prior reports of high voltage GaN-on-Si MISHEMTs [2], and [3]. The $\mathrm{Al}_{\mathrm{x}} \mathrm{Ga}_{1-\mathrm{x}} \mathrm{N}$ barrier had thickness of $\sim 30 \mathrm{~nm}$ with $\mathrm{Al}$ composition of $\sim 25 \%$. The barrier was grown on an unintentionally 
doped $\mathrm{GaN}$ buffer of thickness $~ 150 \mathrm{~nm}$ which in turn was grown on a semi insulating GaN buffer layer of $\sim 1 \mu \mathrm{m}$. These MISHEMTs had multiple field-plates placed in a stairway fashion along the gate-to drain access region.The dimensions of these field plates were optimized to achieve a breakdown voltage in excess of $600 \mathrm{~V}$.The maximum drain current at $\mathrm{V}_{\mathrm{GS}}=0 \mathrm{~V}$ was $\sim 0.45 \mathrm{~A} / \mathrm{mm}$. The $2 \mathrm{DEG}$ concentration and mobility measured by HallEffect measurements on vanderPauw structures were $1 \times 10^{13} \mathrm{~cm}^{-2}$ and $1900 \mathrm{~cm}^{2} / \mathrm{Vs}$, respectively.A separate part of the same wafer (as the MISHEMT) but with no insulating dielectric was used to fabricate semi-transparent Schottky diode teststructures using a process described elsewhere [21].

Thermal and optically assisted de-trapping phenomena in the fully processed MISHEMTs were investigated using modified $\mathrm{CI}_{\mathrm{D}}$-DLTS/DLOS methods [11-16]. The transistors measured hereare switched from pinch-off with $V_{G S}=-10 \mathrm{~V}$ and off-state $V_{D S}$ (ranging from $10 \mathrm{~V}$ to up to $400 \mathrm{~V}$ ) for $100 \mathrm{~ms}$. Following the fill pulse, $\mathrm{V}_{\mathrm{DS}}$ is dynamically controlled to maintain a constant drain-current $I_{D S \text {,const. }}=0.42 \mathrm{~mA} / \mathrm{mm}$ in the triode regime with $\mathrm{V}_{\mathrm{GS}}=0 \mathrm{~V}$ from $2 \times 10^{-3} \mathrm{~s}$ to $10^{4} \mathrm{~s}$. This high $\mathrm{V}_{\mathrm{DS}}$ off-state fill pulse promotes electron trapping in the drain access region, the effect of which is then recorded as a $V_{D S}$ transient during the measurement phase. The resulting $V_{D S}$ time-transient may be converted to an $\mathrm{R}_{\mathrm{ON}}$ time-transient (with units of $\Omega$-mm) using the simple relation $\mathrm{R}_{\mathrm{ON}}$ $=\Delta V_{\mathrm{DS}} / \mathrm{I}_{\mathrm{DS} \text {,const. }}$ The $\mathrm{R}_{\mathrm{ON}}$ transients are recorded at different temperatures for the same off-state $\mathrm{V}_{\mathrm{DS}}(=250 \mathrm{~V}$ here $)$. To extract individual trap time constants and signal amplitude, isothermal box-car DLTS analysis $[22,23]$ was performed on the $R_{\mathrm{ON}}$ transients. The resulting isothermal $\mathrm{CI}_{\mathrm{D}}$-DLTSspectra for each temperature provides a spectrum of the characteristic time constant(s) $\tau$ of the participatingtrap(s). The box-car 
analysis was performed with times $t_{1}$ and $t_{2}$ defining the edges of the box-car rate window with $t_{2}=2.5 \times t_{1}$. The ratio between $t_{2}$ and $t_{1}$ is defined by a constant $\beta(=2.5$ here $)$. The $t_{1}$ was varied from $2 \mathrm{~ms}$ to $4000 \mathrm{~s}$ and consequently the $t_{2}$ varied between $5 \mathrm{~ms}$ and $10000 \mathrm{~s}$. The isothermal $\mathrm{CI}_{\mathrm{D}}$-DLTS plots were created using the expressions:

$$
\begin{aligned}
& \Delta \mathrm{R}_{\mathrm{ON}}=\left(\frac{\beta^{\beta /(\beta-1)}}{\beta-1}\right) *\left[\mathrm{R}_{\mathrm{ON}}\left(t_{1}\right)-\mathrm{R}_{\mathrm{ON}}\left(t_{2}\right)\right] \ldots \\
& \tau=\left(t_{2}-t_{1}\right) / \ln \left(t_{2} / t_{1}\right) \ldots \ldots \ldots \ldots \ldots \ldots \ldots \ldots \ldots \ldots \ldots \ldots
\end{aligned}
$$

where $\mathrm{R}_{\mathrm{ON}}\left(t_{1}\right)$ and $\mathrm{R}_{\mathrm{ON}}\left(t_{2}\right)$ are the values of on-resistance recorded at times $t_{1}$ and $t_{2}$ respectively. For an electron emission process, the $\mathrm{R}_{\mathrm{ON}}\left(t_{2}\right)<\mathrm{R}_{\mathrm{ON}}\left(t_{1}\right)$, the calculated $\Delta \mathrm{R}_{\mathrm{ON}}$ values plotted are negative in sign according to the convention adopted in Eqn (1). The first term in Eqn(1) is a correction factor [22, 23] required to account for the full amplitude of the $\mathrm{R}_{\mathrm{ON}}$ transient (assuming a pure exponential decay process). For $\beta=2.5$ this correctionis $\sim 3.07$. The isothermal $\mathrm{R}_{\mathrm{ON}}$ transients measured at different temperatures can be used to extract the signature activation energy and thermal capture cross-section of the traps responsible $[22,23]$. The thermal based methodsare sensitive to drain-access region traps having thermal activations energies less than approximately $1 \mathrm{eV}$ due to temperature limitations of the cryogenic stage.

To probe even deeper drain-access region traps that are not easily thermally activated, drain-controlled $\mathrm{CI}_{\mathrm{D}}$-DLOS was performed where the sample is illuminated with a tunable sub-bandgap monochromatic light source to enable photoionization of thedeeper levels. For the $\mathrm{CI}_{\mathrm{D}}$-DLOS measurements, the MISHEMT was switched using a fill pulse of $\mathrm{V}_{\mathrm{GS}}=-10 \mathrm{~V}$ and $\mathrm{V}_{\mathrm{DS}}=250 \mathrm{~V}$ for $10 \mathrm{~s}$, and this fill pulse was followed by a measurement in the linear regime at a constant current of $\mathrm{I}_{\mathrm{DS}}=0.42 \mathrm{~A} / \mathrm{mm}$ at $\mathrm{V}_{\mathrm{GS}}=0 \mathrm{~V}$. 
The steady state $\mathrm{R}_{\mathrm{ON}}$ was monitored for different values of optical photon energy. The optically-induced deep level emission causes negative onsets in the steady state $\mathrm{R}_{\mathrm{ON}}$, which represent the activation energies of the deep-levels referred from the conduction band edge $\mathrm{E}_{\mathrm{C}}$. The $\mathrm{R}_{\mathrm{ON}}$ step heights were used to estimate the sheet trap concentrationn $\left(\mathrm{cm}^{-2}\right)$, using [11-16]:

$$
n_{T}=\left(n_{s}\right)^{2}\left[n_{s}-\frac{L_{d e p}}{q \mu_{n} \Delta R_{O N}}\right]^{-1}
$$

where $\mathrm{L}_{\mathrm{dep}}$ is the lateral depletion of the 2DEG channel in the MISHEMT during the offstate high $\mathrm{V}_{\mathrm{DS}}$ fill-pulse that for simpler HEMT structures is determined using ananalytical model previously published by Arehart et al. [13]. Given that the MISHEMT devices used here have complex field plate geometries, and very high electric fields, this simple analytical model cannot be directly applied here. From Eqn (3) it is evident that for large values of $\Delta R_{O N}, n_{T}$ tends approximate $n_{S}$, irrespective of the value of $L_{\text {dep. }}$. When the results are presented, it will be shown that the $\Delta \mathrm{R}_{\mathrm{ON}}$ is indeed large for the MISHEMTs studied here and therefore the impact of $\mathrm{L}_{\mathrm{dep}}$ on estimated $\mathrm{n}_{\mathrm{T}}$ is negligiblebecause $n_{T}$ approximates $n_{s}$ for all values of $L_{d e p}$.

The two terminal AlGaN/GaN Schottky diode structures were investigated using constant capacitance deep level optical spectroscopy,CC-DLOS [24, 25] to evaluate deep levels without the presence of dielectrics and the complex high electric field distribution of the MISHEMT, so that vertical resolution of the deep trap distribution could be realized $[24,25] . I n$ the CC-DLOS measurement, a $10 \mathrm{~s}$ fill pulse at $0 \mathrm{~V}$ was used to set the Schottky diode into accumulation. Following the fill pulse the Schottky device was 
biased to a capacitance value of $\sim 11 \mathrm{nF} / \mathrm{cm}^{-2}$ (at Schottky gate voltage of roughly $-4.7 \mathrm{~V}$ ) which was maintained constant using a dynamic voltage control circuit. This constant capacitance condition ensures a total depletion of $\sim 700 \mathrm{~nm}$ (i.e. much larger than the AlGaN barrier thickness $\sim 30 \mathrm{~nm}$ ), of which $670 \mathrm{~nm}$ depletion was into the $\mathrm{GaN}$ indicating that $\sim 96 \%$ of the depletion region was in the GaN buffer. The sub-bandgap tunable optical excitation of the sample was performed using a monochromatic light source to enable detection of very deep traps in the system. The steady state voltage required to maintain a constant capacitance of $\sim 11 \mathrm{nF} / \mathrm{cm}^{2}$ was recorded for different energies of incident light. The change in the voltage during the measurement corresponds to the change in charge due to charge emission from traps. Given that the GaN depletion used was $\sim 96 \%$ of the total depletion, the CC-DLOS results mostly represent traps and other optical activity limited to the GaN buffer. The results will bear this out because even the AlGaN bandgap cannot be detected for the CC-DLOS measurements of the Schottky structures, meaning the CC-DLOS detrapping response is emanating amost entirely from the GaN buffer traps. More details about CC-DLOS for studying bulk semiconductor states are in [25].

In addition to CC-DLOS the Schottky diodes were explored using surface potential based nanometer scale-DLOS methods to investigate traps physically located above the 2DEG (AlGaN or surface traps) $[26,27]$. This technique is a scanning probe microscope approach that enables measurements of light-induced local surface potential transient measurements with nm-scale spatial resolution [26, 27]. The scanning--DLOS experimental setup consists of a commercial Park XE-NSOM AFM system integrated with a custom built Xe-lamp based tunable sub-bandgap monochromatic light source. 
The light from a $1000 \mathrm{~W}$ Xe lamp was spectrally resolved using a Cornerstone 260 monochromator and delivered to the sample through a custom fiber optics bundle. The biasing of the Schottky metal (with respect to the Ohmic terminal contacting the 2DEG) was achieved using a function generator. Custom designed electronics, software, and feedback techniques were adopted to optimize the time response of the measured surface potential transient Vsp. The localized surface potential transients of the Schottky diode under test were recorded between the Schottky metal and Ohmic contact of the test structures using switching conditions identical to those used in the CC-DLOS measurement. Spectrally resolved sub-bandgap monochromatic light over $1.2 \mathrm{eV}$ to 4.3 $\mathrm{eV}$ was used to illuminate the structure while recording the steady state value of the surface potential transients thus resulting in scanning-DLOS spectra.

\section{Results and Discussion}

Figure 1 shows the on-resistance transients recorded for different off-state high $\mathrm{V}_{\mathrm{DS}}$ conditions. The results indicate that there is no significant increase in the onresistance for off-state $\mathrm{V}_{\mathrm{DS}}$ voltages up to $150 \mathrm{~V}$. However for drain-voltage exceeding $250 \mathrm{~V}$, a very large and persistent on-resistance signal is measured, signifying an almost total current collapse in the MISHEMT being measured. Given enough time (in this case > 3 hours), the on-resistance recovers back to the original static $\mathrm{R}_{\mathrm{ON}}$ value the HEMT had before application of the high voltages.A possible mechanism describing this slow $\mathrm{R}_{\mathrm{ON}}$ recovery process will be presented later in this paper. Figure 2 shows $R_{\mathrm{ON}}$ values recorded for the MISHEMT at $\mathrm{t}=1 \mathrm{~s}$ after the fill pulse. A clear onset is observed at offstate $\mathrm{V}_{\mathrm{DS}} \sim 200 \mathrm{~V}$. This increase in resistance is not due to $\mathrm{V}_{\mathrm{T}}$ (threshold voltage) - shifts 
because very little $\mathrm{V}_{\mathrm{T}}$ change $(<100 \mathrm{mV}$ ) was observed in the MISHEMT during the high off-state $\mathrm{V}_{\mathrm{DS}}$ switching. On the contrary, this large dynamic $\mathrm{R}_{\mathrm{ON}}$ is consistent with high field-induced electron trapping effects in the drain access region. Based on three terminal capacitance measurements similar to previous reports [2, 17] the drain-to-gate capacitance was measured with the $\mathrm{V}_{\mathrm{GS}}<\mathrm{V}_{\mathrm{T}}$ versus $\mathrm{V}_{\mathrm{DS}}$. With increasing $\mathrm{V}_{\mathrm{DS}}$, the channel under the field plates begin to deplete. If the $V_{D S}$ is large enough to deplete all the 2DEG electrons under a given field plate, an increased effective separation between the gate and drain occurs results in a sudden drop or step in $\mathrm{C}_{\mathrm{GD}}$. Multiple such steps were detected in the $\mathrm{C}_{\mathrm{GD}}$ where each step corresponds to a field plate [2], [17]. For voltages exceeding $\mathrm{V}_{\mathrm{DS}}=200 \mathrm{~V}$ and beyond, no more steps were observed in the three terminal high voltage $\mathrm{C}_{\mathrm{GD}}-\mathrm{V}_{\mathrm{DS}}$ characteristics indicating that the lateral depletion in the device has extended beyond the longest field plate. These results suggest that the peak electric field was at the edge of last field plate for $V_{D S}>200 \mathrm{~V}$ which means that the onset in Fig. 2 is due to the electron trapping occurs primarily at the edge of the longest field plate.The strong dependence of the $\mathrm{R}_{\mathrm{ON}}$ signal to the off-state $\mathrm{V}_{\mathrm{DS}}$ is indicative of a virtual-gating process similar to what has been reported previously in RF GaN HEMTs at lower voltage switching conditions $[12,13]$. The $\mathrm{R}_{\mathrm{ON}}$ recovery as a function of time suggests electron emission from the traps that allows the local2DEG and therefore the $\mathrm{R}_{\mathrm{ON}}$ to recover as a function of time.

The $\mathrm{R}_{\mathrm{ON}}$ transient measurements at room temperature were recorded for different baseplate temperatures to explore the temperature dependence of the transient time constants to possibly identify any activation energies of the traps involved. Figure 3 shows this data collected for a given off-state $\mathrm{V}_{\mathrm{DS}}$ switched from $250 \mathrm{~V}$. Interestingly at 
low temperatures, little $\mathrm{R}_{\mathrm{ON}}$ degradation was observed. To examine the time constants of these transients, isothermal DLTS analysis of the transients was performed.For a given temperature, the negative peaks in the isothermal $\mathrm{CI}_{\mathrm{D}}$-DLTS data represents the characteristic time-constant of the transient at that temperature. The Arrhenius plot extracted from this data is plotted in Fig. 4(b) reveals a thermal activation energy of 0.02 $\mathrm{eV}$ and a non-physically small thermal capture cross-section of $1 \times 10^{-28} \mathrm{~cm}^{2}$.The Arrhenius data of a typical thermally activated trap (for example, $\mathrm{E}_{\mathrm{C}}-0.57 \mathrm{eV}$ level) from previous works[12-14] is plotted as example to contrast against the Arrhenius data from the $\mathrm{R}_{\mathrm{ON}}$ recovery transientshown in Fig. 4(b). Typical thermally activated traps(such as the $\mathrm{E}_{\mathrm{C}}-0.57 \mathrm{eV}$ ) havetheir characteristic electron emission time constant vary by at least 3 orders of magnitude over $\sim 100 \mathrm{~K}$ temperature change. However the trap(s) associated with the $\mathrm{R}_{\mathrm{ON}}$ transients, in this work,shows no evidence of a typical thermal process. If the $\mathrm{R}_{\mathrm{ON}}$ recovery process in these MISHEMTs were truly thermally activated, then change of baseplate temperature would change the characteristic emission time constant by several orders of magnitude over the given temperature range. However as it is shown in Fig. 4(a), the peak positions hardly changed as a function of temperature. A less than $\sim 2 \mathrm{x}$ change was observed for an increase in $100 \mathrm{~K}$ of base plate temperature. Later in this paper, wepropose a modeldescribing why the emission of the traps possibly follows this non-thermally activated process in theMISHEMTs.

The non-thermally activated process prevents determination of the trap energies using traditional DLTS-based approaches and so to overcome this, the trap energies were determined using optical stimulation (i.e. using $\mathrm{CI}_{\mathrm{D}}$-DLOS). The results of the optical spectroscopy on the MISHEMT are shown in Fig. 5. In the MISHEMT, the $\mathrm{R}_{\mathrm{ON}}$ after off- 
state $\mathrm{V}_{\mathrm{DS}}=250 \mathrm{~V}$ application is persistently high at $\sim 150 \Omega$-mm and is independent of light with energy $<2 \mathrm{eV}$. This high on-resistance state of the MISHEMT caused by severe drain-access region electron trapping affecting the local 2DEG is shown in Fig. 6(a). Forincident DLOS light energies $>2 \mathrm{eV}$, photoionization of a $\sim \mathrm{E}_{\mathrm{C}}-2 \mathrm{eV}$ trap recovers the entire $R_{O N}$ and this recovered state is captured in Fig. $6(b)$. This large $\Delta R_{O N}$ amplitude can be used to estimate a (sheet) trap density using the Eqn. 3.The estimated trap density $\mathrm{n}_{\mathrm{T}}$ is very large (between $9.8 \times 10^{12} \mathrm{~cm}^{-2}$ and $1 \times 10^{13} \mathrm{~cm}^{-2}$ ) and almost approaches $n_{\mathrm{s}}$ for assumed values of $L_{\text {dep }}$ ranging from as large as $10 \mu \mathrm{m}$ to as small as 1 nm.As was previously discussed, this apparent insensitivity of estimated $n_{T}$ to $L_{d e p}$ is due to the large measured $\Delta \mathrm{R}_{\mathrm{ON}}$ value used as input toEqn (3).

With the $\mathrm{E}_{\mathrm{C}}-2.0 \mathrm{eV}$ activation energy of the dominant trap associated with the $\mathrm{R}_{\mathrm{ON}}$ degradation identified, the concentration of this defect and its physical location are now explored. In the transistor with its intricate geometry and complex vertical and lateral electric fields at high voltages, it is difficult to distinguish whether the trapped charge occurs above or below the 2DEG, similar toprevious reports [17]. To mitigate this, CC-DLOS and scanning-DLOS methods were applied to the two-terminal AlGaN/GaN Schottky diodes for which lateral fields and transistor design issues are not present, so that complementary "materials-based" measurements could be made to augment the HEMT-based characterization results, as described next.

As seen in Fig. 7, the CC-DLOS results of the AlGaN/GaN Schottky diode shows a negative onset at $\sim \mathrm{E}_{\mathrm{C}}-2 \mathrm{eV}$ that matches the $\sim \mathrm{E}_{\mathrm{C}}-2 \mathrm{eV}$ trap signature detected using $\mathrm{CI}_{\mathrm{D}}$-DLOS in the MISHEMT (shown in the same figure for convenience). Furthermore, the CC-DLOS onset at $\mathrm{E}_{\mathrm{C}}-3.28 \mathrm{eV}$ is characteristic of a much-studied level in $\mathrm{n}-\mathrm{GaN}$ 
that has been attributed to residual carbon impurities [21, 28, 29], and serves as a marker that the CC-DLOS spectrum is dominated by levels in the GaN buffer. This is further supported by the fact that there is no evidence of any feature associated with the AlGaN bandedge(only the $\mathrm{GaN}$ bandedge is seen) or any other state between $\sim 3.7 \mathrm{eV}-4 \mathrm{eV}$ that have been previously $[21,30]$ associated with AlGaN levels in CC-DLOS spectra. These observations combined with the fact that that there is also no dielectric layer present in these Schottky test structures, provides strong indication that the $\sim \mathrm{E}_{\mathrm{C}}-2 \mathrm{eV}$ level resides within the GaN buffer, and by corollary, is therefore unrelated to the AlGaN, its surface or its interface with $\mathrm{GaN}$.

Direct evidence that the $\mathrm{E}_{\mathrm{C}}-2.0 \mathrm{eV}$ trap is located in the $\mathrm{GaN}$ buffer demonstratedby the application of scanning-DLOSmeasurements that were performed in the openings between the Schottky gate and the Ohmic contact where the AlGaN surface was exposed as shown in Fig. 8.The figure shows a cross-sectional view of the $\mathrm{AlGaN} / \mathrm{GaN}$ test structure over which the local Vsp was recorded. The 2DEG in the HEMT acts as a ground plane during the surface potential measurements and therefore screens any charge below the 2DEG making the measurement sensitive only to traps above the 2DEG in the AlGaN barrier [26, 27]. Figure 9 shows the steady state surface potential trap signal collected as a function of incident optical energy. Negative onsets represent electron traps in the AlGaN bulk or surface. The noteworthy point hereis the complete absence of the $\mathrm{E}_{\mathrm{C}}-2 \mathrm{eV}$ trap and all other known $\mathrm{GaN}$ related features such as the $\mathrm{E}_{\mathrm{C}}-3.28 \mathrm{eV}$ trap and the GaN bandgap observed earlier in the CC-DLOS data (Fig. 7). Instead, only AlGaN-related features were observed, namely an $\mathrm{E}_{\mathrm{C}}-3.7 \mathrm{eV}$ trapthat 
has been reported previously [21] and the AlGaN bandedge near $4 \mathrm{eV}$.This result provides further confirmationthat the $\mathrm{E}_{\mathrm{C}}-2 \mathrm{eV}$ trap is only present in the $\mathrm{GaN}$ buffer.

With the experimental evidencedescribed, which shows the $E_{C}-2 \mathrm{eV}$ trap that causes current collapse at high voltage switching appears to be a buffer trap, we now consider the physical process for the current collapse through this trap using a simple analytical model. The bulk concentration of the $\mathrm{E}_{\mathrm{C}}-2 \mathrm{eV}$ trap necessary to completely pinch-off the MISHEMT was estimated using simple calculations. If for the sake of argument it is assumed that the $\mathrm{E}_{\mathrm{C}}-2 \mathrm{eV}$ traps are uniformly distributed over $3 \mu \mathrm{m}$ of the GaN buffer, then $1 \times 10^{13} \mathrm{~cm}^{-2}$ sheet concentration corresponds to $\sim 3 \times 10^{16} \mathrm{~cm}^{-3}$ bulk concentration. This is a reasonable value because the $\mathrm{E}_{\mathrm{C}}-2 \mathrm{eV}$ trap has been previously detected in bulk GaN within bulk concentrations up to $1.4 \times 10^{16} \mathrm{~cm}^{-3}$ [28]. On the other hand, if the $\mathrm{E}_{\mathrm{C}}-2 \mathrm{eV}$ trap were assumed to be contained within the $30 \mathrm{~nm}$ thick $\mathrm{AlGaN}$ barrier, the correspondingrequired bulk concentration of this trap in the AlGaNbarrier would be $\sim 3 \times 10^{18} \mathrm{~cm}^{-3}$. This very high estimate is unreasonable because of two reasons. First, close examination of previous reports on DLOS studies in bulk AlGaN have not revealed an $\mathrm{E}_{\mathrm{C}}-2 \mathrm{eV}$ trap in bulk $\mathrm{AlGaN}$ [30]. Secondly, the estimated bulk concentration of the $\mathrm{E}_{\mathrm{C}}-2 \mathrm{eV}$ trap is $10 \mathrm{X}$ larger than the total concentration of all traps previously reported in bulk $\mathrm{AlGaN}[30]$. It is therefore very unlikely that this $\mathrm{E}_{\mathrm{C}}-2 \mathrm{eV}$ trap could occur especially in such high concentrations in the AlGaN film of the transistors and diodes under study.

It is now quite clear that the $\mathrm{E}_{\mathrm{C}}-2 \mathrm{eV}$ defect is located in the $\mathrm{GaN}$ buffer. Given that this level was detected in the Schottky diode test structures where no high voltage electric stressing was applied to have formed this defect in any localized fashion, this trap 
was likely to be present uniformly in the buffer layer, both under the gate and in the access regions of the MISHEMT. However, the modulation of these traps is highly localized at the field plate edge because this process is likely triggered by the electric fields that peak at the field plate edges in the structures during the application of high off state $\mathrm{V}_{\mathrm{DS}}(>200 \mathrm{~V})$. It is therefore the combination of the uniform presence of this preexisting $\mathrm{E}_{\mathrm{C}}-2 \mathrm{eV}$ trap in large bulk concentrations $\left(\sim 3 \times 10^{16} \mathrm{~cm}^{-3}\right)$ and the occurrence of localized peak electric fields at the field plate edges that is responsible for the observed $\mathrm{R}_{\mathrm{ON}}$ degradation and the related total current collapse in these MISHEMTs. To better understand how this trap causes current collapse, a simple physical model is proposed that accounts for the filling and emptying of this trap (i.e. its modulation) under high off-state $\mathrm{V}_{\mathrm{DS}}$, in spite of its deep position in the bandgap and semi-insulating nature of the buffer layer. Figure 10 represents our proposed model. The energy band diagrams plotted as Figs 10(b) and 10(c) represent those extracted along a vertical cutline yy' [shown in Fig. 10(a)] taken just beyond the longest field plate. Before application of any high voltage in equilibrium conditions, the occupancy of the $2 \mathrm{eV}$ trap in the GaN buffer is shown in Fig. 10(b). Because we have already assumed that the Fermi level of the buffer is likely to be located at or below the $2 \mathrm{eV}$ trap, only the traps located closer to the AlGaN/GaN interface are filled with electrons and therefore ionized. The occurrence of filled $\mathrm{E}_{\mathrm{C}}-2 \mathrm{eV}$ traps before application of any high voltage is validated by the CC-DLOS results in shown in Fig.7. The detection of $E_{C}-2$ eV traps in the two terminal Schottky diode structures where nohigh fieldswere applied, proves that it is not necessary for high fields to exist to be able detect the $\mathrm{E}_{\mathrm{C}}-2 \mathrm{eV}$ signature in the Schottky diodes. What was detected in the CC-DLOS measurements is simply the small fraction of the filled or 
ionized $\mathrm{E}_{\mathrm{C}}-2 \mathrm{eV}$ traps near the $\mathrm{AlGaN} / \mathrm{GaN}$ interface that remains filled by virtue of its location below the Fermi level at $\mathrm{V}_{\mathrm{GS}}=0 \mathrm{~V}$ in the dark. These previously filled $\mathrm{E}_{\mathrm{C}}-2 \mathrm{eV}$ levels detrap on the application reverse bias and in the presence of light with photon energy $h v>2 \mathrm{eV}$. During the fill pulse, however, these same traps close to the $\mathrm{AlGaN} / \mathrm{GaN}$ interface get refilled on the application of $\mathrm{V}_{\mathrm{GS}}=0 \mathrm{~V}$ fill pulse for 10 s thereby restoring the device.However in the MISHEMT, for this level to have a massive impact on the transistor terminal characteristics, it is essential that an large number oftraps including ones far into the buffer also participate. Their participation is enabled by the application of high electric field during the high off-state $\mathrm{V}_{\mathrm{DS}}$ switching.

During the application of high off-state $V_{D S}(>200 V)$, the very high electric fields localized at the edge of the field plates can cause massive localized electron injection in the $\mathrm{E}_{\mathrm{C}}-2 \mathrm{eV}$ trap deep into the $\mathrm{GaN}$ buffer through mechanisms such as Zener tunneling, hot carrier injection, reverse gate leakage among several others [17, 18]. With the traps now filled with electrons, the energy band diagrams of the transistor soon after the high voltage fill pulse are as shown in Fig. 10(c). The additional negative charge now present in the system causes a severe back-gating effect that almost completely pinches off the 2DEG and causes the large $\mathrm{R}_{\mathrm{ON}}$ effect. The transistor recovers from this stateand reverts back to state represented in Fig. 10(b) when exposed to light with photon energies $>2 \mathrm{eV}$ that emit trapped electrons. Figure 11 shows the energy band-diagrams of the HEMT along a horizontal cutlineresented before and after the high voltage application. Fig. 11(a) shows that the cutline is obtained in deep the GaN buffer. In equilibrium conditions shown in Fig. 11(b), the $\mathrm{E}_{\mathrm{C}}-2 \mathrm{eV}$ trap remains free of electrons because it lies above the Fermi level this deep in the GaN buffer. In Fig. 11(c) the non-equilibrium energy band 
diagrams soon after the application of high voltage are shown. The peak electric fields occurring at the edge of the field plate caused localized electron trapping only at the edge of the field plate. This massive electron trapping causing the high degree of band bending that prevent lateral conduction of electron from the source to the drain thereby increasing the $\mathrm{R}_{\mathrm{ON}}$ manifold. As mentioned earlier, waiting for long times recovers the transistor to its original state. This recovery is possible because of discharging of the $E_{C}-2 e V$ trap through a non-thermally assisted process akin to a tunneling mechanism. Theshape of this band diagrams shown in Fig. 11(c)soon after the high voltage off-state fill pulse provides an explanation for how such very deep $\mathrm{E}_{\mathrm{C}}-2 \mathrm{eV}$ traps can recover within a few hours when a traditional thermal detrapping process from such a deep level would have typically taken several decades.Similar observations and models were also presented by Jin et al. in [17].

\section{Conclusion}

In conclusion, spatially sensitive optical and thermal trap spectroscopies were applied to GaN/Si MISHEMTs. A deep $\sim \mathrm{E}_{\mathrm{C}}-2 \mathrm{eV}$ electron trap was shown to be responsible for the observed $\mathrm{R}_{\mathrm{ON}}$ degradation of the device that occurs soon after high voltage (>200V) switching. This trap is activated at the edge of the field plate on application of high voltages (>200V) and shows characteristics similar to that of previously detected virtual-gate traps [12]-[13].Detailed comparison with AlGaN/GaN Schottky diodes suggests that this trap is located within the GaN buffer, and does not appear to be related to the $\mathrm{AlGaN}$ barrier or surface states. The severe $\mathrm{R}_{\mathrm{ON}}$ degradation phenomenon, which is a pressing problem in these MISHEMT devices, may be greatly 
used through a combination of (a) judicious epitaxial growth and design strategies targeted to mitigate the concentrations of electrically active defects in the MISHEMT (especially in the buffer) and (b) field management practices including but not limited to enhanced field plate design strategies and control of 2DEG density to reduce fields without compromising performance.

\section{Acknowledgements}

The work at The Ohio State University was supported by the Semiconductor Research Corporation under task \#2298.001 and by the Office of Naval Research (ONR) through the Design-for-Reliability Initiative for Future Technologies (DRIFT) MURI program (monitored by Dr. P. Maki).

\section{REFERENCES}

[1] K. Boutros, S. Burnham, D. Wong, K. Shinohara, B. Hughes, D. Zehnder, and C. McGuire, "Normally-off 5A/1100 V GaN-on-Si device for high voltage applications," inIEDM Tech. Dig., 2009, pp. 7.5.1-7.5.3.

[2] R. Chu, A. Corrion, M. Chen, R. Li, D. Wong, D. Zehnder, B. Hughes, and K. Boutros, "1200 V Normally off GaN-on-Si field effect transistors with low dynamic on-resistance," IEEE Electron Device Lett., vol. 32, pp. 632-634, 2011.

[3] M. Van Hove, S. Boulay, S. Bahl, S. Stoffels, X. Kang, D. Wellekens, K. Geens, A. Delabie, and S. Decoutre, "CMOS process-compatible high power low leakage AlGaN/GaN MISHEMT on Silicon," in IEEE Electron Device Lett., vol. 33, pp. 667-669, 2012.

[4] W. Saito, T. Nitta, Y. Kakiuchi, Y. Saito, K. Tsuda, I. Omura, and M. Yamaguchi, "Suppression of dynamic on-resistance increase and gate charge measurements in high voltage GaN HEMTs with optimized field plate structure," IEEE Trans. Electron Devices, vol. 54, 1825-1830, 2007.

[5] W. Saito, Y. Kakiuchi, T. Nitta, Y. Saito, T. Noda, H. Fujimoto, A. Yoshioka, T. Ohno, and M. Yamaguchi, "Field-plate structure dependence of current collapse phenomena in high voltage GaN HEMTs," IEEE Electron Device Lett., vol. 31, pp. 659-661, 2010. 
[6] E. Feltin, B. Beaumont, M. Laügt, P. de Mierry, P. Vennéguès, H. Lahrèche, M. Leroux, and P. Gibart, "Stress control in GaN grown on silicon (111) by metalorganic vapor phase epitaxy," Appl. Phys. Lett., vol. 79, pp. 3230-3232, 2001.

[7] X. Pan, M. Wei, C. Yang, H, Xiao, C. Wang, and X. Wang, "Growth of GaN film on Si (111) substrate using AlN sandwich structure," J. Cryst. Growth, vol. 318, pp. 464-467, 2011.

[8] S. Binari, K. Ikossi, J. Roussos, W. Kruppa, D. Park, H. Dietrich, D. Koleske, A. Wickenden, and R. Henry, "Trapping effects and microwave power performance in AlGaN/GaN HEMTs," IEEE Trans. Electron Devices, vol. 48, pp. 465-471, 2001.

[9] G. Meneghesso, G. Verzellesi, R. Pierobon, F. Rampazzo, A. Chini, U. Mishra, C. Canali, and E. Zanoni, "Surface-related drain current dispersion effects in AlGaNGaN HEMTs," IEEE Trans. Electron Devices, vol.51, 1554 (2004).

[10] J. Joh and J. del Alamo, "A current-transient methodology for trap analysis for GaN high electron mobility transistors," IEEE Trans. Electon Devices, vol. 58, pp. 132140, 2011.

[11] A. Arehart, A. Malonis, C. Poblenz, Y. Pei, J. Speck, U. Mishra, and S. Ringel, "Next generation defect characterization in nitride HEMTs," Phys. Status Solidi C, vol. 8, pp. 2242-2244, 2011.

[12] A. Arehart, A. Sasikumar, G. Via, B. Winningham, B. Poling, E. Heller, and S. Ringel, "Spatially-discriminating trap characterization methods for HEMTs and their application to RF-stressed AlGaN/GaN HEMTs," inIEDM Tech. Dig., 2010, pp. 20.1.1-20.1.4.

[13] A. Arehart, A. Sasikumar, S. Rajan, G. Via, B. Poling, B. Winningham, E. Heller, D. Brown, Y. Pei, F. Recht, U. Mishra, and S. Ringel, "Direct observation of $0.57 \mathrm{eV}$ trap-related RF output power reduction in $\mathrm{AlGaN} / \mathrm{GaN}$ high electron mobility transistors," Solid-State Electron., vol. 80, pp. 19-22, 2013.

[14] A. Sasikumar, D. W. Cardwell, A. R. Arehart, J. Lu, S. Kaun, S. Keller, U. K. Mishra, J. S. Speck, J. P. Pelz, and S. A. Ringel, "Toward a physical understanding of the reliability-limiting $\mathrm{E}_{\mathrm{C}}-0.57 \mathrm{eV}$ trap in GaN HEMTs," in IEEE Intl. Reliab. Phys. Symp., pp. 2.C.1.1-6, 2014.

[15] A. Sasikumar, A. Arehart, S. Kolluri, M. Wong, S. Keller, S. DenBaars, J. Speck, U. Mishra, and S. Ringel, "Access region defect spectroscopy of DC-stressed N-polar GaN MISHEMTs,"IEEE Electron Device Lett., vol. 33, pp. 658-660, 2012.

[16] A. Sasikumar, A. Arehart, S. Kaun, M. Wong, U. Mishra, J. Speck, and S. Ringel, "Direct correlation between specific trap formation and electric stress-induced degradation in MBE-grown AlGaN/GaN HEMTs," in IRPS Tech. Dig., 2012, pp. 2.C.3.1-2.C.3.6.

[17] D. Jin, J. Joh, S. Krishnan, N. Tipirneni, S. Pendharkar, and J. A. del Alamo, "Total current collapse in high voltage GaN MIS-HEMTs induced by Zener trapping," in IEDM Tech. Dig., pp. 6.2.1-6.2.4, 2013.

[18] J. Joh, N. Tipirneni, S. Pendharkar, and S. Krishnan, "Current collapse in GaN heterojunction field effect transistors for high-voltage switching applications," in IEEE Intl. Reliab. Phys. Symp., pp. 6C.5.1-6C.5.4, 2014. 
[19] D. Jin and J. del Alamo, "Methodology for the study of dynamic ON-resistance in high-voltage GaN field-effect transistors," IEEE Trans. Electron Devices, vol. 60, pp. 3190-3196, 2013.

[20] D. Jin and J. del Alamo, "Impact of high-power stress on dynamic ON-resistance of high-voltage GaN HEMTs," Microelectron. Reliab., vol. 12, pp. 2875-2879, 2012.

[21] A. Armstrong, A. Chakraborty, J. Speck, S. DenBaars, U. Mishra, and S. Ringel, "Quantitative observation and discrimination of $\mathrm{AlGaN}$ - and GaN-related deep levels in $\mathrm{AlGaN} / \mathrm{GaN}$ heterostrucutures using capacitance deep level optical spectroscopy," Appl. Phys. Lett., vol. 89, 2621161-3, 2006.

[22] V. Turchanikov, V. Lysenko, and V. Gusev, "Isothermal DLTS method using sampling time scanning," Phys. Status Solidi A, vol. 95, pp. 283-289, 1986.

[23] D. Schroder, Semiconductor Material and Device Characterization (Wiley, New Jersey, 2005) 3rd ed., p. 278 (2005).

[24] C. Jackson, A. Arehart, E. Cinkilic, B. McSkimming, J. Speck, and S. Ringel, "Interface trap characterization of atomic layer deposition $\mathrm{Al}_{2} \mathrm{O}_{3} / \mathrm{GaN}$ metalinsulator-semiconductor capacitors using optically and thermally based deep level spectroscopies," J.Appl. Phys., vol. 113, pp. 2045051-6, 2013.

[25] J. Vilanova, S. Duenas, E. Rubio, L. Bailon, J. Barbolla, and E. Lora-Tamayo, "Constant-capacitance deep-level optical spectroscopy," Sol. State Electon., vol. 32, pp. 287-293, 1989.

[26] D. W. Cardwell, A. R. Arehart, C. Poblenz, Y. Pei, J. S. Speck, U. K. Mishra, S. A. Ringel, and J. P. Pelz, "Nm-scale measurements of fast surface potential transients in an $\mathrm{AlGaN} / \mathrm{GaN}$ high electron mobility transistor," Appl. Phys. Lett., vol. 100, pp. 1935071-4, 2012.

[27] D. W. Cardwell, A. Sasikumar, A. R. Arehart, S. W. Kaun, J. Lu, S. Keller, J. S. Speck, U. K. Mishra, S. A. Ringel, and J. P. Pelz, "Spatially-resolved spectroscopic measurements of $\mathrm{E}_{\mathrm{C}}-0.57 \mathrm{eV}$ traps in $\mathrm{AlGaN} / \mathrm{GaN}$ high electron mobility transistors,", Appl. Phys. Lett.,vol. 102, pp. 1935091-4, 2013.

[28] A. Armstrong, A. R. Arehart, D. Green, U. K. Mishra, and J. S. Speck, "Impact of deep levels on the electrical conductivity and luminescence of gallium nitride codoped with carbon and silicon," J. Appl. Phys., vol. 98, pp. 0537041-11, 2005.

[29] A. Armstrong, A. Arehart, B. Moran, S. DenBaars, U. Mishra, J. Speck, and S. Ringel, "Impact of carbon on trap states in n-type GaN grown by metalorganic chemical vapor deposition," Appl. Phys. Lett., vol. 84, pp. 374-376, 2004.

[30] A. Arehart, A. Allerman, S. Ringel, "Electrical characterization of n-type $\mathrm{Al}_{0.3} \mathrm{Ga}_{0.7} \mathrm{~N}$ Schottky diodes," J. Appl. Phys., vol. 109, pp. 1145061-10, 2011. 


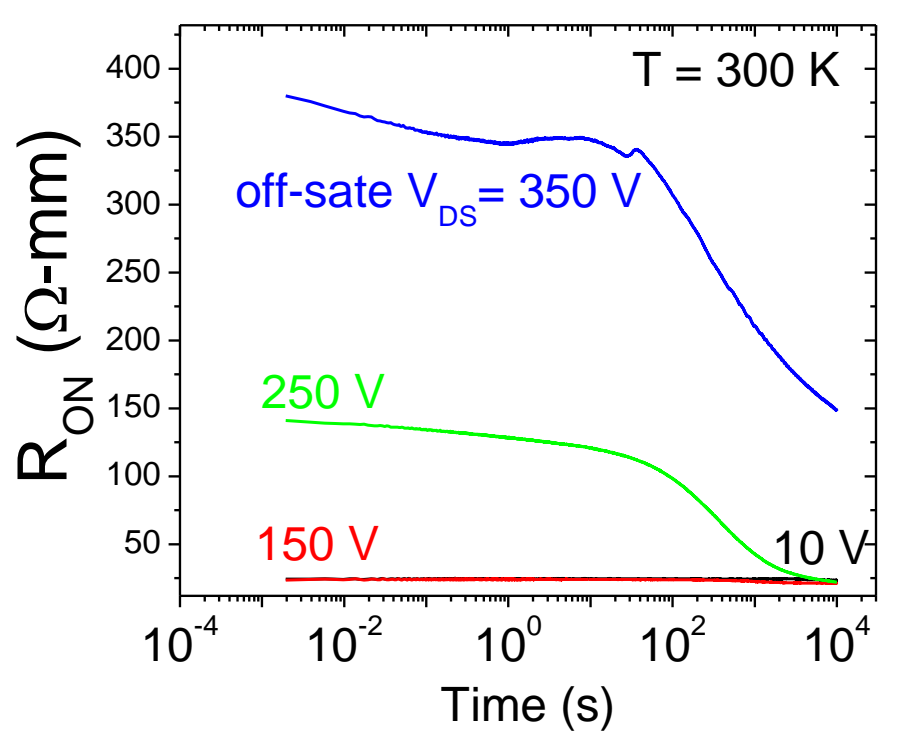

Figure 1On-resistance transients recorded for different off-state $\mathrm{V}_{\mathrm{DS}}$ conditions. Up to $150 \mathrm{~V}$ off-state $\mathrm{V}_{\mathrm{DS}}$, no significant increase in dynamic on-resistance was observed. For off-state $\mathrm{V}_{\mathrm{DS}}$ cases at and above $250 \mathrm{~V}$ very large and persistent $\mathrm{R}_{\mathrm{ON}}$ was observed which then tend to recover to steady state $\mathrm{R}_{\mathrm{ON}}$ case at very long times (>10 $0^{4}$ seconds).

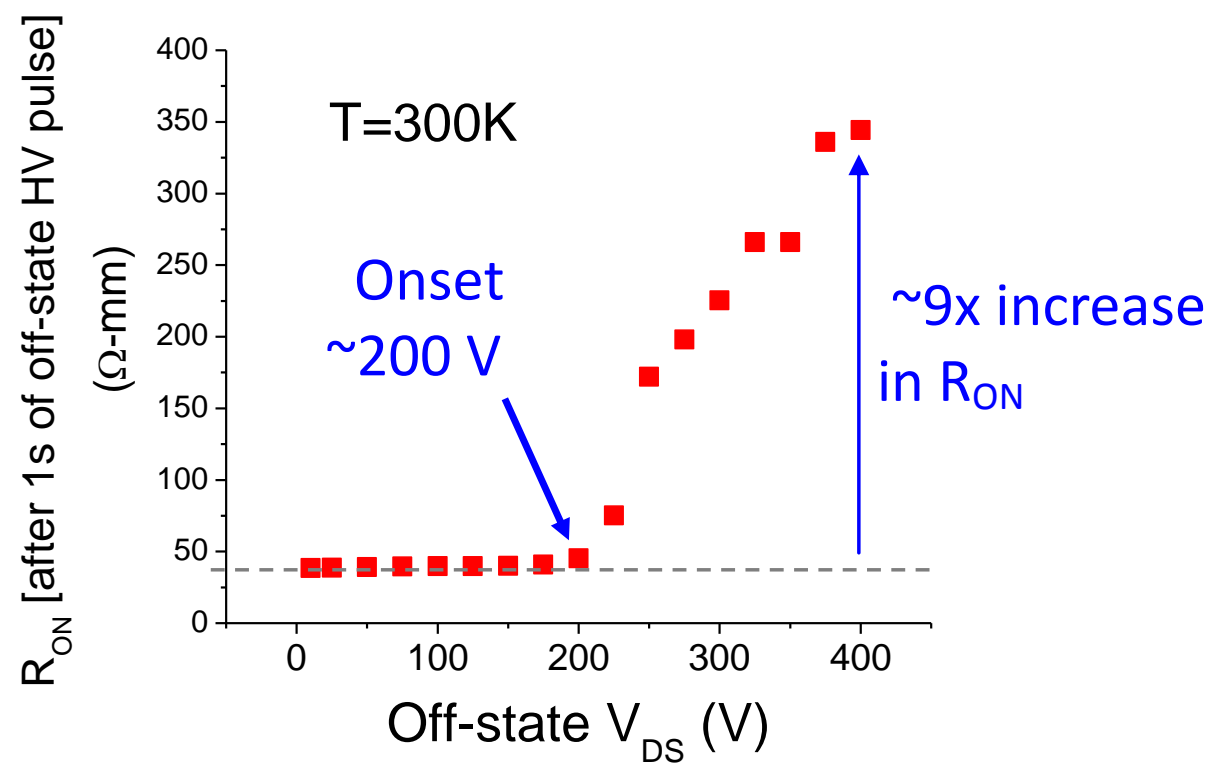

Figure 2On-resistance sampled at $1 \mathrm{~s}$ after switching the MISHEMT as discussed in Fig. 1 for different off-state drain voltages. A sharp onset at $200 \mathrm{~V}$ indicates that significant on-resistance increases take place only after the threshold electric field is exceeded at the edge of the longest field plate where the electron trapping occurs. 


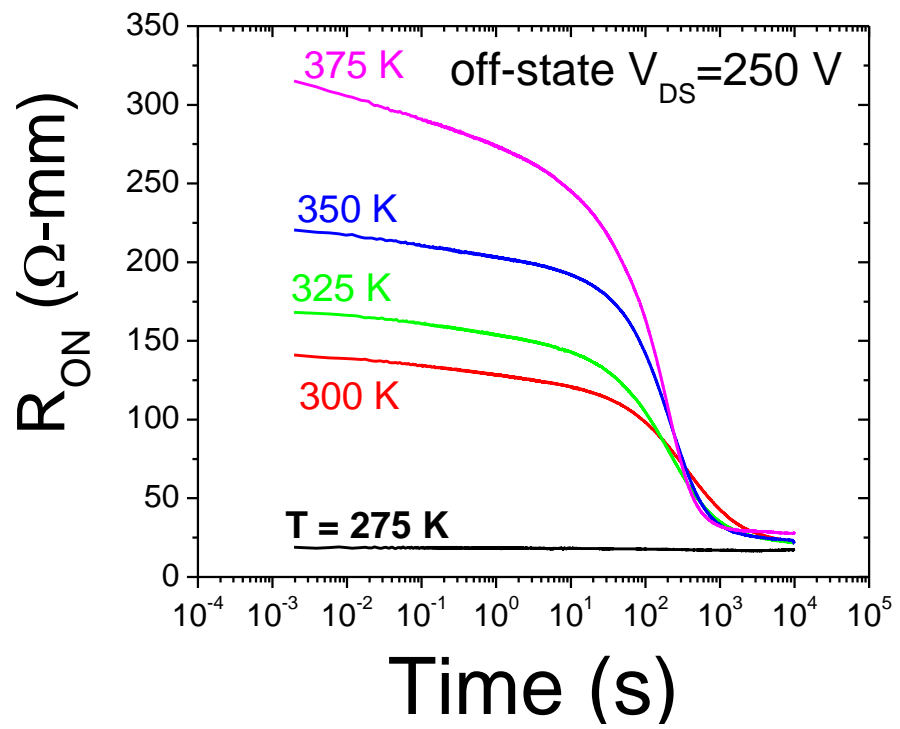

Figure 3On-resistance transients recorded for off-state $\mathrm{V}_{\mathrm{DS}}=250 \mathrm{~V}$ switching conditions at different baseplate temperatures. The amplitude of the on-resistance transient has a strong temperature dependence whereas the time constant seems mostly unaffected. Closer inspection of time-constants for a give temperature is obtained using iso-thermal DLTS analysis of these transients shown in the Fig. 4(a).

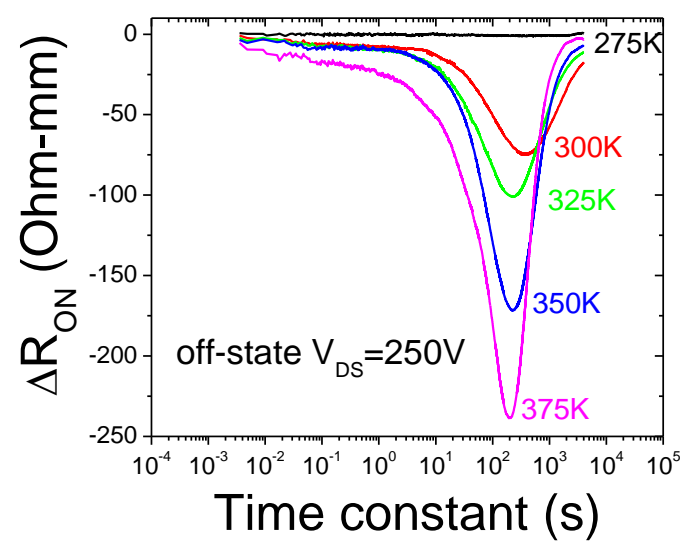

(a)

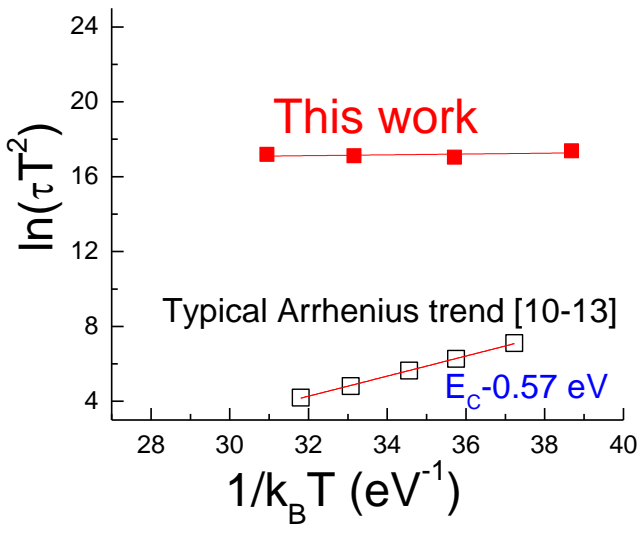

(b)

Figure 4 (a) Iso-thermal $\mathrm{CI}_{\mathrm{D}}$-DLTS analysis of $\mathrm{R}_{\mathrm{ON}}$ transients reveal characteristic timeconstant of the respective transients for that given temperature. The time-constant of the transient features observed is mostly independent of temperature unlike a traditional thermally activated trap. This fact is illustrated from the Arrhenius plot shown in 4(b). The extracted thermal activation energy of this process (shown as closed symbols) is 0.02 $\mathrm{eV}$ and apparent thermal capture cross-section $\sim 1 \times 10^{-28} \mathrm{~cm}^{2}$ which is non-physical and very different from the Arrhenius data of a thermally detected traditional $\mathrm{E}_{\mathrm{C}}-0.57 \mathrm{eV}$ trap. These results reveal that the $\mathrm{R}_{\mathrm{ON}}$ recovery phenomenon here is not a typical thermally activated process. 


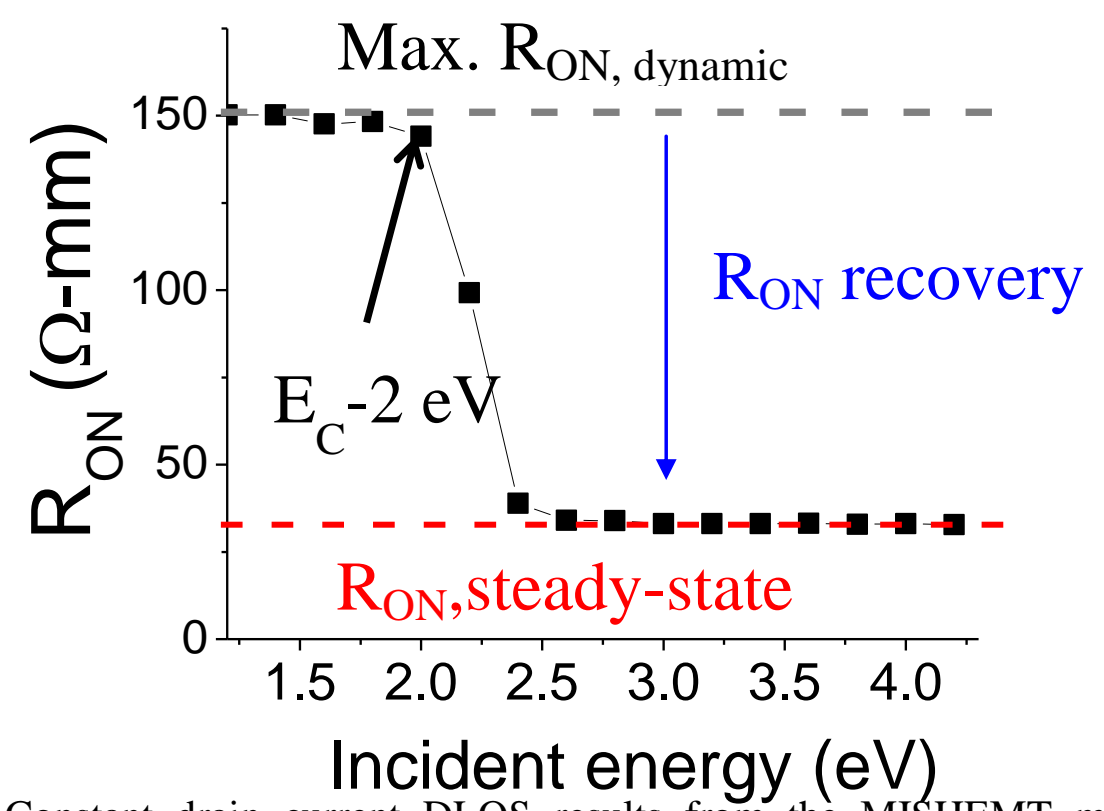

Figure 5 Constant drain current DLOS results from the MISHEMT measured as a function of the high voltage switching. In the dark and at incident photon energies $<2 \mathrm{eV}$ the on-resistance remained persistently high $(\sim 150 \mathrm{Ohm}-\mathrm{mm})$ soon after switching from off-state $\mathrm{V}_{\mathrm{DS}}=250 \mathrm{~V}$ case. The application of light energies $>2 \mathrm{eV}$ recovers the onresistance to the original steady state values $\sim 30 \mathrm{Ohm}-\mathrm{mm}$. The sharp negative onset at 2 $\mathrm{eV}$ informs us of an $\mathrm{E}_{\mathrm{C}}-2 \mathrm{eV}$ electron trap directly linked to this $\mathrm{R}_{\mathrm{ON}}$ degradation effect.

(a)

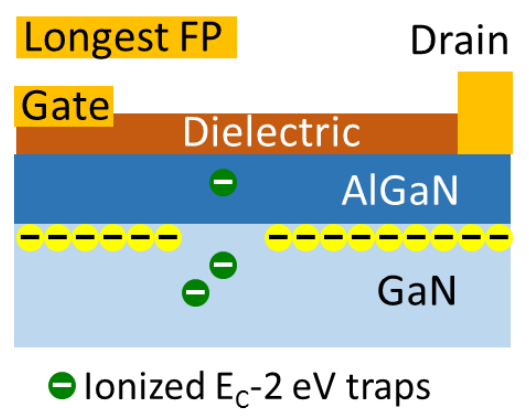

(b)

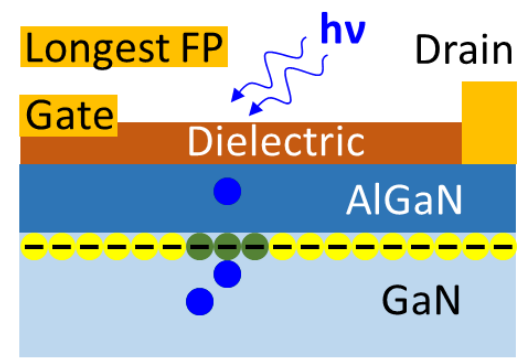

$\mathrm{E}_{\mathrm{C}}-2$ eV trap after electron emission Recovered electrons in 2DEG

Figure 6 Schematic cross-sections of the MISHEMT showing the charge state of the $\mathrm{E}_{\mathrm{C}}-$ $2 \mathrm{eV}$ trap (a) soon after high off-state $\mathrm{V}_{\mathrm{DS}}$ switching in the darkand (b) after shining light energies $>2 \mathrm{eV}$. The high voltage induces trapping of electrons in the $\mathrm{E}_{\mathrm{C}}-2 \mathrm{eV}$ trap mostly at the edge of the field plate, thereby causing a reduction of 2DEG charge density and a massive increase in on-resistance. The electrons from the $\mathrm{E}_{\mathrm{C}}-2 \mathrm{eV}$ are emitted using sub-bandgap monochromatic light energies exceeding $2 \mathrm{eV}$ in photon energy. This electron emission results in 2DEG recovery and reduction of on-resistance to original steady state values before application of any high off-state $\mathrm{V}_{\mathrm{DS}}$. 


\section{Schottky test structure}

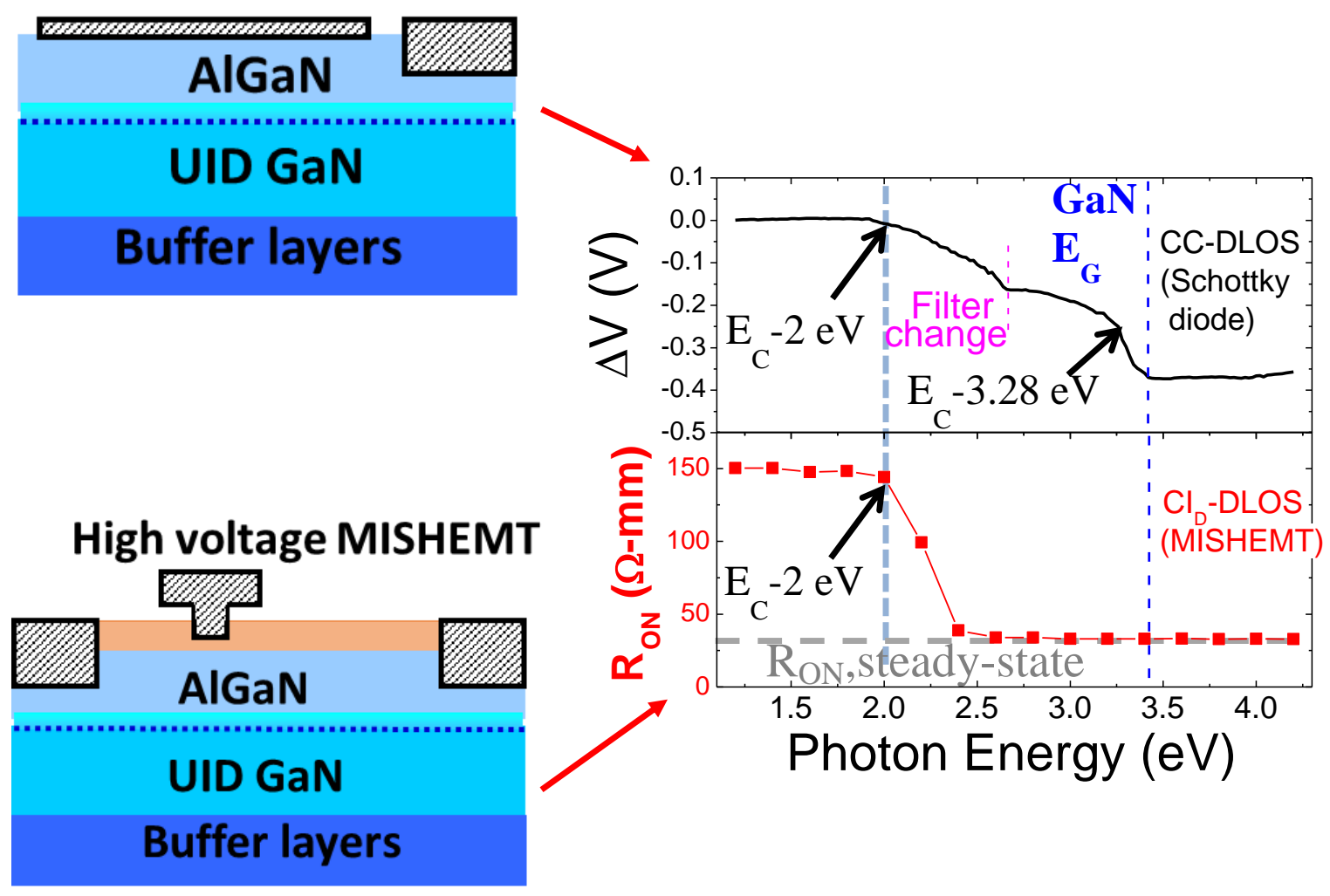

Figure 7 CC-DLOS results from the AlGaN/GaN Schottky diode switched compared against $\mathrm{CI}_{\mathrm{D}}$-DLOS from the MISHEMT. Both the MISHEMT and the diode show the same $\mathrm{E}_{\mathrm{C}}-2 \mathrm{eV}$ trap feature which proves that this feature is unrelated to the dielectric in the MISHEMT. Also, the CC-DLOS from the Schottky diode reveals the $\mathrm{E}_{\mathrm{C}}-3.28 \mathrm{eV}$ trap, a well known GaN defect in addition to the GaN bandedge. The absence of tell-tale $\mathrm{AlGaN}$ features in the Schottky diode CC-DLOS spectra is not surprising given that this measurement was performed with the depletion in the GaN being $~ 96 \%$ of the total depletion. 


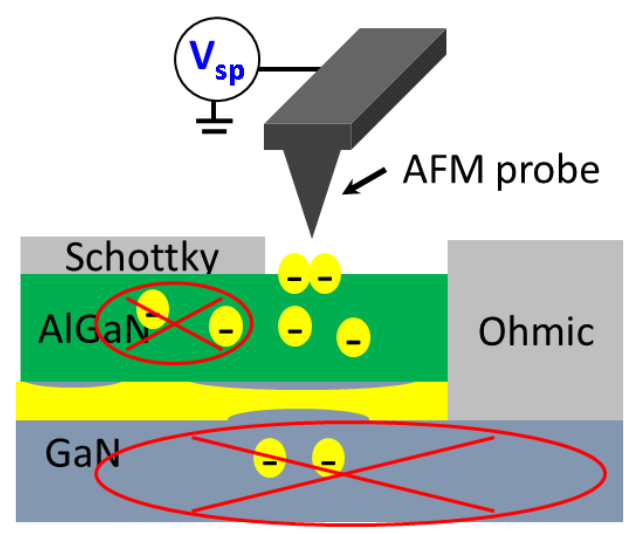

Figure 8 Schematic showing the nano-scale vertical and lateral sensitivity of the AFM probe tip used in the scanning-DLOS measurements.

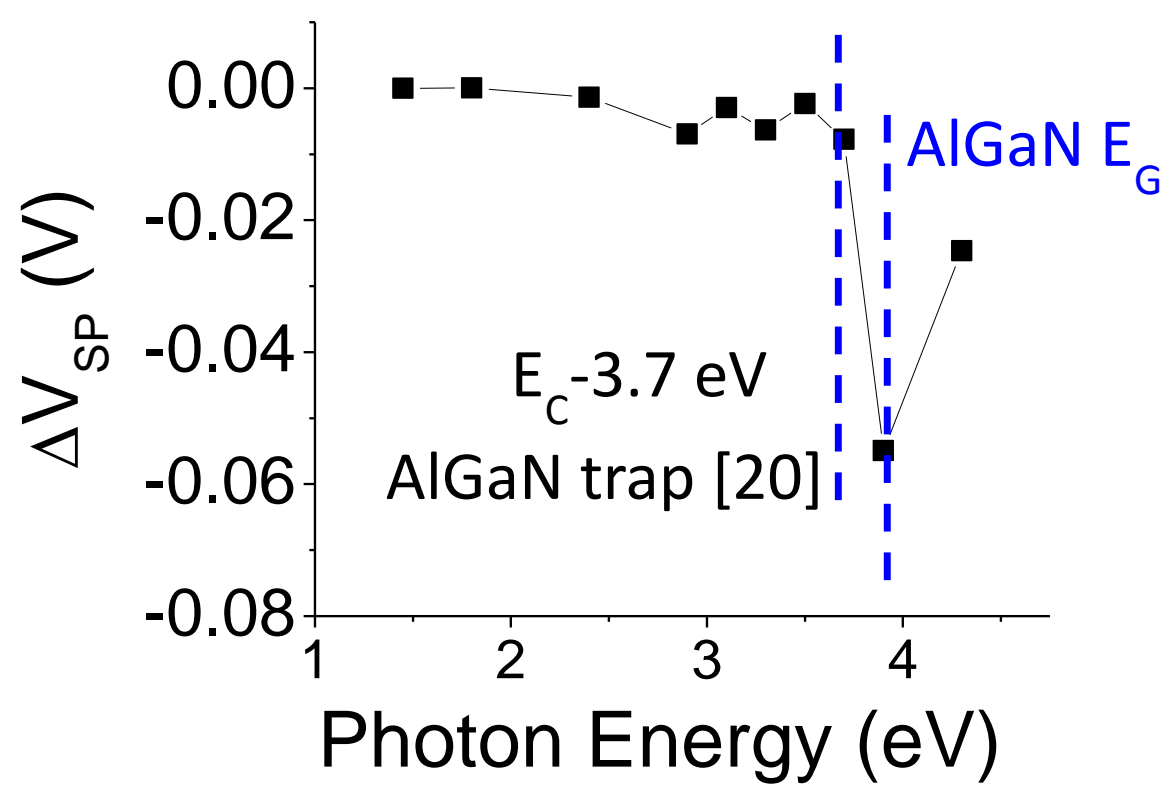

Figure 9 Nano-scale DLOS data sensitive to AlGaN surface potential transients reveal no sign of the $\mathrm{E}_{\mathrm{C}}-2 \mathrm{eV}$ trap despite switching the Schottky diode in the same scheme as the CC-DLOS. An $\mathrm{E}_{\mathrm{C}}-3.7 \mathrm{eV}$ AlGaN trap signature and the AlGaN bandedege were detected in the surface potential spectra underscoring the ability to this technique to monitor traps exclusively in the AlGaN film. 

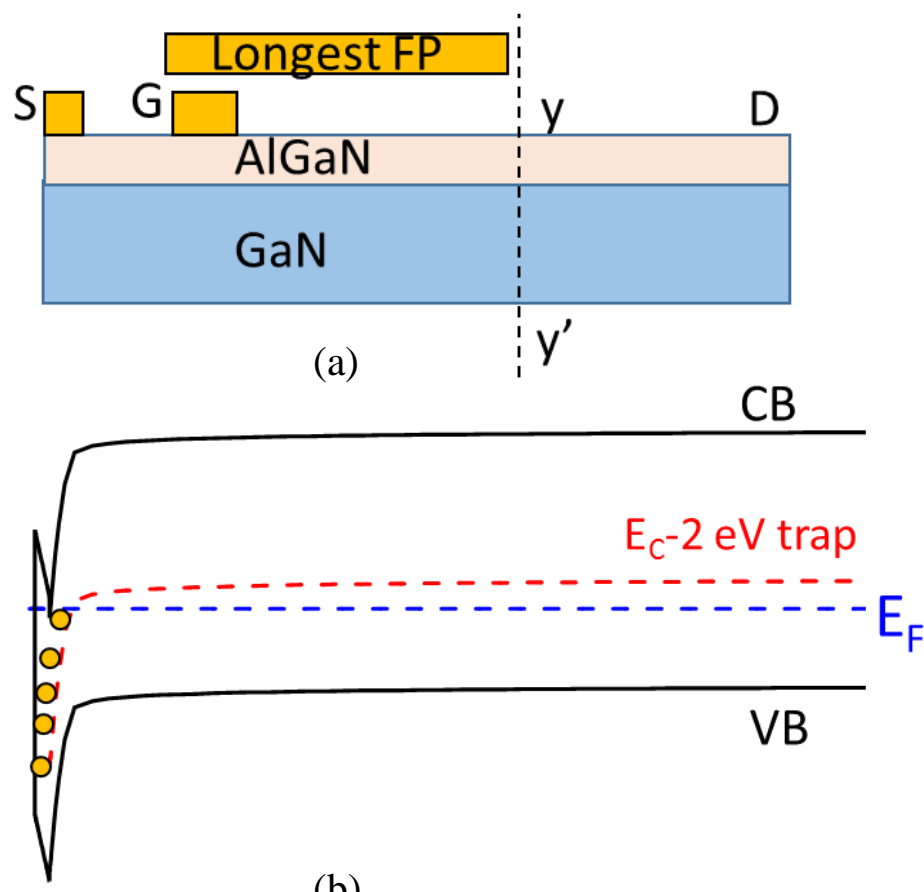

(b)

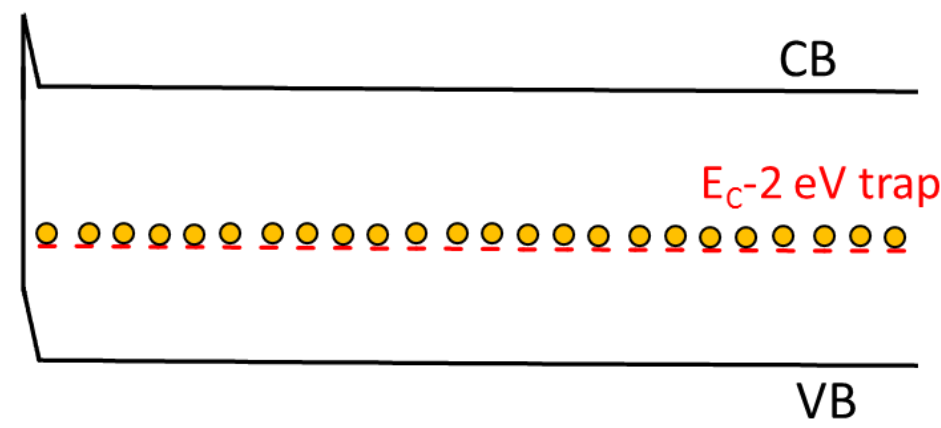

(c)

Figure 10 (a) Shows schematic cross-section of the HEMT and a vertical cutlineyy'just beyond the longest field plate. The corresponding energy band-diagrams along this cutline are plotted in (b) equilibrium, and (c) in non-equilibrium soon after high off-state $\mathrm{V}_{\mathrm{DS}}$ application. Assuming the Fermi level is energetically located below the $2 \mathrm{eV}$ trap, only the traps physically close (i.e. few hundred $\mathrm{nm}$ ) to the AlGaN barrier/GaN buffer interface are filled with electrons during equilibrium. The $\mathrm{E}_{\mathrm{C}}-2 \mathrm{eV}$ trap located deeper in the $\mathrm{GaN}$ remains unfilled. After application of high voltages and high electric fields at the edge of the field plate, localized electron trapping causes substantial filling of the $E_{C}-2$ $\mathrm{eV}$ trap deep in the buffer resulting in a localized pinch-off of the 2DEG in the drain access region and very high on-resistance values. 


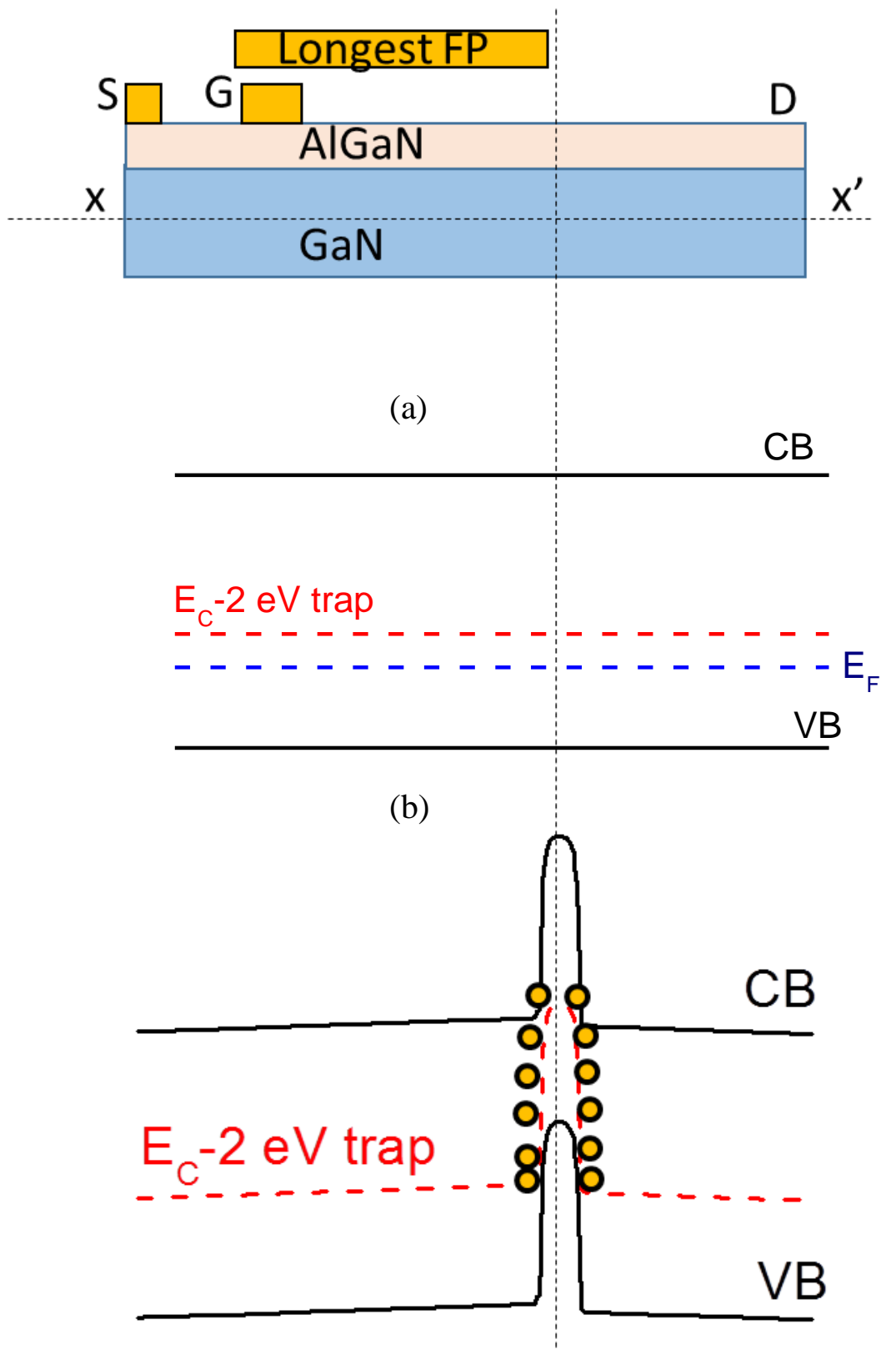

(c)

Figure 11 (a) Shows schematic cross-section of the HEMT and a horizontal cutline xx' deep in the GaN buffer. The corresponding energy band-diagrams along this cutline are plotted in (b) equilibrium, and (c) in non-equilibrium soon after high off-state $\mathrm{V}_{\mathrm{DS}}$ application. After application of high voltages and high electric fields at the edge of the field plate, localized electron trapping in the $\mathrm{E}_{\mathrm{C}}-2 \mathrm{eV}$ trap deep in the GaN buffer resultsin severe localized band bending and almost complete pinch-off of the 2DEG in the drain thereby causing the large $\mathrm{R}_{\mathrm{ON}}$ degradation. The severely distorted banddiagrams shown in low field non-equilibrium conditions in Fig 10(c) could explain how 
the $\mathrm{E}_{\mathrm{C}}-2 \mathrm{eV}$ emits electrons as a function of time through an atypical non-thermally activated process. 